\title{
1 Stress activity is not predictive of coping style in North American red squirrels
}

3 Sarah E. Westrick ${ }^{1^{*}}$, Freya van Kesteren ${ }^{1}$, Rupert Palme ${ }^{2}$, Rudy Boonstra ${ }^{3}$, Jeffery E. Lane ${ }^{4}$, Stan

4 Boutin $^{5}$, Andrew G. McAdam 6 , Ben Dantzer ${ }^{1,7}$

$5 \quad{ }^{1}$ Department of Psychology, University of Michigan, Ann Arbor, MI, USA

$6 \quad{ }^{2}$ Department of Biomedical Sciences, University of Veterinary Medicine, Vienna, Austria

$7 \quad{ }^{3}$ Department of Biological Sciences, University of Toronto Scarborough, Toronto, ON, Canada

$8 \quad{ }^{4}$ Department of Biology, University of Saskatchewan, Saskatoon, SK, Canada

$9 \quad{ }^{5}$ Department of Biological Sciences, University of Alberta, Edmonton, AB, Canada

$10 \quad{ }^{6}$ Department of Integrative Biology, University of Guelph, Guelph, ON, Canada

$11{ }^{7}$ Department of Ecology and Evolutionary Biology, University of Michigan, Ann Arbor, MI, USA

$12 *$ Corresponding author: westse@umich.edu, 623-687-8615

14 Keywords: coping styles, glucocorticoids, North American red squirrels, behavioral syndromes

\section{Acknowledgments}

17 We thank Agnes MacDonald and her family for long-term access to her trapline, and the

18 Champagne and Aishihik First Nations for allowing us to conduct our work within their

19 traditional territory. We thank Adi Boon, Amanda Kelley, and Ryan W. Taylor for collecting

20 much of the behavioral data and all the volunteers, field assistants, and graduate students for

21 their assistance in data collection. This work was supported by American Society of

22 Mammalogists to SEW; University of Michigan to SEW and BD; National Science Foundation

23 (IOS-1749627) to BD; and Natural Sciences and Engineering Research Council to SB, AGM, JL,

24 and RB. This is publication XX of the Kluane Red Squirrel Project. 


\section{Abstract}

26 Individuals vary in their behavioral and physiological responses to environmental changes. These

27 behavioral responses are often described as 'coping styles' along a proactive-reactive continuum.

28 Studies in laboratory populations often, but not always, find that behavioral responses and

29 physiological responses to stressors covary, where more proactive (more aggressive and active)

30 individuals have a lower physiological stress response, specifically as measured by

31 hypothalamic-pituitary-adrenal (HPA) axis activity. These studies support the possibility of

32 hormonal pleiotropy underlying the presentation of behaviors that make up the proactive-reactive

33 phenotype. However, recent research in wild populations is equivocal, with some studies

34 reporting the same pattern as found in many controlled laboratory studies, whereas others do not.

35 We tested the hypothesis that physiological and behavioral stress responses are correlated in wild

36 adult North American red squirrels (Tamiasciurus hudsonicus). We used fecal cortisol

37 metabolites (FCMs) as a non-invasive, integrated estimate of circulating glucocorticoids for our

38 measurement of HPA axis activity. We found that FCM concentrations were not correlated with

39 three measures of behavioral coping styles (activity, aggression, and docility) among individuals.

40 This does not support the hypothesis that hormonal pleiotropy underlies a proactive-reactive

41 continuum of coping styles. Instead, our results support the "two-tier" hypothesis that behavioral

42 and physiological stress responses are independent and uncorrelated traits among individuals in

43 wild populations that experience naturally varying environments rather than controlled

44 environments. If also found in other studies, this may alter our predictions about the evolutionary

45 consequences of behavioral and endocrine coping styles in free-living animals. 


\section{Significance Statement}

50 Individuals vary in how they respond to stressors through behavior and physiology, but we find

51 the two responses are independent in wild animals. Many laboratory studies find links between

52 the behavioral and physiological stress responses, however studies conducted with wild

53 populations are less conclusive. In wild North American red squirrels, independence between the

54 physiological response and behavioral response may allow adaptive responses to a changing

55 environment without pleiotropic constraint.

\section{Introduction}

Organisms can respond to fluctuating environmental challenges and aversive stimuli both

60 through behavioral responses and physiological stress responses. Laboratory studies often find

61 these responses to be associated with one another (but see Steimer and Driscoll 2003; Koolhaas

62 et al. 2007). In behavioral ecology and behavioral neuroscience, 'coping styles' have been

63 recognized as one method of categorizing behavioral reactions to environmental challenges and

64 stressors. Coping styles refer to a consistent set of behavioral responses to a stressor (Gosling

65 2001; Réale et al. 2007; Koolhaas et al. 2010; Stamps and Groothuis 2010). Furthermore, the

66 suite of behaviors that make up an individual's coping style is theorized to be mediated by

67 hormones that exert pleiotropic actions (Koolhaas et al. 1999; McGlothlin and Ketterson 2008).

68 This unidimensional model has been repeatedly supported by studies describing how the

69 hypothalamic-pituitary-adrenal (HPA) axis mediates coping styles (Koolhaas et al. 1999). Many

70 of these studies have used selected lines, or have been done under controlled conditions in the

71 laboratory. The conclusion from this model is that the behavioral stress response and

72 physiological stress response run along the same axis. This hypothesis suggests a unidimensional 
73 response along a proactive-reactive continuum, where 'proactive' individuals are highly

74 aggressive, highly active, and exhibit lower HPA axis reactivity and activity compared to

75 'reactive' individuals (Koolhaas et al. 1999; Cockrem 2007; Carere et al. 2010). The vast

76 majority of these studies have been conducted using laboratory animals or wild animals selected

77 for specific behavioral phenotypes, producing individuals at the extremes of this behavioral

78 continuum. For example, in wild Great Tits (Parus major) lines selected for divergent

79 personality types show the predicted unidimensional relationship between behavioral and stress

80 responses in that more proactive birds exhibited lower HPA axis reactivity in response to capture

81 and restraint (Baugh et al. 2012), and lower baseline corticosterone metabolites (Stöwe et al.

82 2010).

As more empirical studies are testing these models, the results from studies in the wild

84 have been equivocal. Whereas there is some support for the unidimensional model in wild

85 animals (see Table 1), recent studies that have used this coping style paradigm to test the

86 relationship between behavior and HPA axis reactivity or activity in free-living animals have

87 found that the proactive-reactive continuum is not predictive of the physiological stress response

88 (Garamszegi et al. 2012; Ferrari et al. 2013; Dosmann et al. 2015). For example, though

89 laboratory selection line results are consistent with predictions of the unidimensional model,

90 when testing Great Tits in the laboratory with natural, non-selected variation in exploratory

91 behavior, the relationship no longer holds (Baugh et al. 2012).

92 Discrepancies in the lab between recent observed relationships (Koolhaas et al. 2007) and

93 the simple unidimensional model (Koolhaas et al. 1999), have recently led to the development of

94 a 'two-tier' coping style model. This two-tier model proposes that individuals in a population can

95 vary independently in both behavioral responses and physiological responses to environmental

96 challenges (Koolhaas et al. 2010). This model of coping styles reframed the original model to 
97 establish behavioral coping strategies on a continuum independent of physiological coping

98 strategies (Koolhaas et al. 2010). The distinction between the unidimensional and two-tier coping

99 style models is significant in assessing the ecological and evolutionary consequences of variation

100 in response to stressors. If the phenotypic correlation between behavioral and physiological

101 stress responses (assumed by the unidimensional coping styles model) reflects an underlying

102 correlation mediated by the effects of a hormone, this may present a limitation in the ability of

103 populations to adapt to changing environmental stressors (Sih et al. 2004; Dantzer and Swanson

104 2017). Alternatively, if the two-tier model of coping style is supported, and there are two

105 separate axes for behavioral and physiological stress responses, this suggests the potential for

106 each trait to be an independent target of selection, potentially facilitating rapid adaptation to new

107 environmental challenges (McGlothlin and Ketterson 2008; Ketterson et al. 2009). Exploring

108 how coping styles relate to the physiological stress response in wild populations allows us to test

109 across the entire spectrum of naturally occurring individual variation in behavioral coping styles,

110 thus informing our perspective on how these mechanisms function in wild populations (Réale et

111 al. 2007; Ferrari et al. 2013).

112 We investigated the relationship between three behavioral traits and one measure of HPA

113 axis activity (concentrations of fecal cortisol metabolites, FCM) in a natural population of North

114 American red squirrels (Tamiasciurus hudsonicus, hereafter, 'red squirrels'). Previous studies in

115 this species showed that there was a repeatable, correlated suite of behavioral traits, specifically

116 aggression, activity, and docility, across the adulthood of an individual (Boon et al. 2007; Taylor

117 et al. 2012). These suites of behavioral traits can also be placed along the proactive-reactive

118 continuum as coping styles, with the more active, aggressive, and less docile individuals at the

119 proactive end of the continuum. Differences in coping styles in red squirrels have clear

120 environment-dependent fitness correlates (Boon et al. 2007, 2008; Taylor et al. 2014), and 
121 variation in heritable coping styles among individuals (Taylor et al. 2012) in this population may

122 be maintained through fluctuating selection caused by changing environmental conditions

123 (Taylor et al. 2014).

124 We used fecal samples as a non-invasive proxy for HPA axis activity and reactivity,

125 which is unaffected by trapping-induced stress (Dantzer et al. 2010). In red squirrels, FCM is

126 representative of the circulating plasma cortisol over the past $\sim 12$ hours, with a $10.9 \pm 2.3$ hours

127 lag time to peak excretion following experimental administration of cortisol (Dantzer et al.

128 2010). Influences of the circadian rhythm on circulating cortisol are not detected in fecal samples

129 collected throughout the day (Dantzer et al. 2010). Additionally, glucocorticoid concentrations in

130 fecal samples have been shown to be representative of HPA activity and reactivity (Sheriff et al.

131 2011; Palme 2019).

132 It is important to note that glucocorticoids are metabolic hormones and only one

133 mediator of the reactive physiological stress response of an individual (Romero et al. 2009).

134 However evidence for both the unidimensional and two-tier models of coping styles specifically

135 connect glucocorticoids with the behavioral response (Table 1), in addition to catecholamines

136 (reviewed in Koolhaas et al. 1999, 2010). While this is not a perfect measure of the overall

137 physiological stress response of an individual, glucocorticoids are an important physiological

138 mediator of the multifaceted stress response (Sapolsky et al. 2000; Romero et al. 2009).

139 Glucocorticoids are secreted to mobilize energy in response to a stressor in the environment, but

140 also exert pleiotropic effects (Sapolsky et al. 2000). For example, fluctuating baseline

141 glucocorticoids act as a mediator of future reproductive investment in European Starlings

142 (Sturnus vulgaris) by preparing individuals for energetically expensive reproductive seasons

143 (Love et al. 2014). 
To test the unidimensional and two-tier models of the overall stress response, we

145 measured FCM as a non-invasive marker of HPA axis activity and the behavior of individuals

146 using three behavioral assays (open-field trial, mirror-image stimulation trial, and handling

147 docility assay) to measure coping style. We then compared the FCM concentrations to the

148 behavioral coping style of individual squirrels. A relationship between FCMs and behavioral

149 coping style across individuals would support the unidimensional model, whereas a lack of

150 relationship would support the two-tier model.

152 Methods

153 Study species

154 North American red squirrels are a sexually monomorphic species of arboreal squirrels

155 (Boutin and Larsen 1993). Females and males are both territorial of their food-cache (located on

156 the center of their territory) year-round (Dantzer et al. 2012; Siracusa et al. 2017). Red squirrels

157 in the region of our study rely on seeds produced by white spruce (Picea glauca) trees as their

158 primary food source (Fletcher et al. 2010). Squirrel population density is closely associated with

159 mast seeding of the white spruce, or episodes of booms and busts in food availability (McAdam

160 and Boutin 2003; Fletcher et al. 2010; Dantzer et al., 2013). Red squirrels have one litter per

161 year, with the exception of mast years when autumn spruce seed is superabundant (Boutin et al.

162 2006; McAdam et al. 2007).

163 Our study was conducted as a part of the Kluane Red Squirrel Project, a long-term study

164 of wild population of red squirrels within Champagne and Aishihik First Nation traditional

165 territory along the Alaska Highway in the southwest Yukon, Canada $\left(61^{\circ} \mathrm{N}, 138^{\circ} \mathrm{W}\right)$. Each

166 squirrel was tagged with a unique set of alphanumeric stamped ear tags (National Band and Tag

167 Company, Newport, KY, USA). At each live-trapping (Tomahawk Live Trap, Tomahawk, WI, 
168 USA) event, body mass and reproductive status of the squirrel were recorded. Female

169 reproductive status was determined through changes in body mass, by nipple condition, and by

170 abdominal palpations of developing fetuses in females. Male reproductive status was determined

171 by palpating for the presence of testicles either in the scrotum (breeding) or abdomen (non-

172 breeding). A more detailed description of the population and general methods can be found in

173 McAdam et al. (2007).

174 The local population of red squirrels was broken down into three study populations in

175 different locations: two were control populations (referred to hereafter as 'control grids') and one

176 was provided with supplemental food between 2004 and 2017, such that squirrel density was

177 increased (Dantzer et al., 2013; hereafter referred to as 'high-density grid'). Squirrels on the

178 high-density grid were provided with $1 \mathrm{~kg}$ of peanut butter (no sugar or salt added)

179 approximately every six weeks from October to May (Dantzer et al. 2012). We included these

180 squirrels to increase our sample size, and included study grid type as a covariate in all models to

181 control for variation between the grids. Additionally, high conspecific competition is a

182 significant environmental factor influencing the physiological stress response of red squirrels

183 (Dantzer et al. 2013) and so was important to include as a covariate in our statistical models

184 (Table 2). All work was conducted under the animal ethics approvals from Michigan State

185 University (AUF\#04/08-046-00) and University of Guelph (AUP\#09R006).

\section{Behavioral trials}

Squirrels were subjected to two behavioral trials to measure 'activity' and 'aggression': an open-field (OF) trial, and a mirror image stimulation (MIS) trial (Boon et al. 2007; Taylor et

190 al. 2012). These behavioral trials were conducted for other projects and were not evenly

191 distributed across years. We performed trials in 2005, 2008, 2009, 2010, and 2012 (see Table 2 
192 for a breakdown of sample sizes). During these years, additional trials were conducted on

193 squirrels in this population for multiple studies (see Boon et al. 2007; Boon et al. 2008; Kelley et

194 al. 2015; Taylor et al. 2012, 2014), but for the purposes of this analyses, we only included trials

195 for which we also had FCM concentration data for that individual. All squirrels were mature

196 adults ( $>1$ year old) at the time of the trial.

197 To measure an individual's coping style, we conducted OF and MIS trials during the

198 same trapping event, with the OF trial completed first followed by the MIS trial. Squirrels

199 habituate to these tests (Archer 1973; Boon et al. 2008; Martin and Réale 2008), but the behavior

200 of individual squirrels over time is known to be repeatable (Boon et al. 2007, 2008; Taylor et al.

201 2014). For simplicity, we thus used only the results of each individual's first test as a measure of

202 its activity and aggression. We transferred focal squirrels from a live trap into the arena using a

203 canvas handling bag. The same portable testing arena was used for both trials, and consisted of a

$20460 \times 80 \times 50 \mathrm{~cm}$ white corrugated plastic box with a clear acrylic lid (Taylor 2012). Four blind

205 holes made with black PVC caps in the bottom of arena allowed the squirrel to explore possible

206 'escape routes'. We exposed a 45 x $30 \mathrm{~cm}$ mirror fixed to one end of the arena after the OF trial

207 to begin the MIS trial. A digital video camera recorded behavior in the arena. We performed all

208 behavioral trials on the territory of the focal individual. Between trials, we cleaned the arena

209 using 70\% isopropyl alcohol.

210 To quantify behavior from the videos, we used manual scoring methods with an ethogram

211 developed and used in previous red squirrel studies (Boon et al. 2007, 2008; Taylor et al. 2012,

212 2014; Kelley et al. 2015; Supplementary Material Table S1). Because these videos were

213 collected and scored across multiple years, observers used different software programs

214 depending on what program was available the year they were scored. Trials conducted in 2005

215 were scored using The Observer Video-Pro 5.0 (Noldus Information Technology, Wageningen, 
216 The Netherlands). Trials conducted from 2008-2010 were scored using JWatcher Video 1.0

217 (Blumstein and Daniel 2007). Trials conducted in 2012 were scored using Cowlog software

218 (Hänninen and Pastell 2009). Regardless of the software used, the ethogram and the overall

219 method of scoring the videos remained consistent. Because this is a manual process and the

220 software simply records keystrokes indicating behaviors observed, it is not likely that the

221 software used impacted the score. Furthermore, a previous study using some of our dataset

222 showed high inter-observer reliability for the behavioral measures we recorded from these videos

223 (Taylor et al., 2012), so it again seems unlikely that the software used would influence the

224 behavioral data we extracted from the videos. During the OF trial, we recorded the mutually

225 exclusive behaviors of time spent walking, sniffing, chewing, rearing, grooming, and being still.

226 Additionally, we recorded the number of jumps and head-dips in the false holes. During the MIS

227 trial, we recorded the amount of time spent in the third of the arena closest to the mirror, and the

228 amount of time spent in the third of the arena farthest from the mirror. We also recorded the

229 number of aggressive contacts with the mirror (attacks), the latency until the first attack, and the

230 latency until the first approach towards the mirror. A detailed description of the video scoring

231 methods can be found in Boon et al. (2008). Following Taylor et al. (2012), behaviors with an

232 inter-observer reliability of greater than 0.7 were used in analyses (see Supplementary Material

233 Table S1 and S2 for a list of behaviors used in the analyses).

As an additional behavioral measurement, we also measured 'docility' of individual

235 squirrels. In 2008 and 2009, docility measurements were collected on many squirrels for other

236 studies (see Boon et al. 2007; Taylor et al. 2012), but for the purposes of this study, we focused

237 only on trials that were conducted during a trapping event where fecal samples were also

238 collected and subsequently analyzed $(n=168$ trapping events). We quantified docility as the

239 squirrel's response to handling (for examples in other species, see Carere and Oers 2004; Martin 
and Réale 2008; Montiglio et al. 2012). We transferred squirrels from the trap into a canvas

241 handling bag and placed the squirrel on a flat surface. We measured docility during handling by

242 counting the number of seconds out of 30 seconds in which the squirrel was not struggling. A

243 squirrel that spent most of the time immobile during the test was considered docile, a trait

244 previously demonstrated to be repeatable (Boon et al. 2007; Taylor et al., 2012) and heritable

245 (Taylor et al., 2012) in this population. This test was conducted an average of $8(\min =1, \max =$

246 42) times on 79 individual squirrels caught between 2008 and 2009. Docility scores were z-

247 scored for analyses. See Table 2 for detailed sample sizes.

Fecal cortisol metabolites

From 2005 to 2014, we opportunistically collected a total of 703 fecal samples during

251 routine trapping of squirrels with peanut butter for measurement of FCM concentrations

252 corresponding to individuals with behavioral data (see Dantzer et al. 2010). Fecal samples were

253 collected from under live-traps within two hours of trapping and placed in $1.5 \mathrm{~mL}$ vials stored in

$254 \mathrm{a}-20^{\circ} \mathrm{C}$ freezer within five hours of collection. Urine contaminated feces were excluded. All

255 fecal samples were lyophilized for 14-16 h before being pulverized in liquid nitrogen using a

256 mortar and pestle. Using $0.05 \mathrm{~g}$ of dry ground feces, steroid metabolites were extracted by

257 adding $1 \mathrm{~mL}$ of $80 \%$ methanol and vortexing samples at $1450 \mathrm{RPM}$ for $30 \mathrm{~min}$, and then

258 centrifuging for $15 \mathrm{~min}$ at $2500 \mathrm{~g}$ (Dantzer et al. 2010; Palme et al. 2013). The resulting

259 supernatant was stored at $-20^{\circ} \mathrm{C}$ for analysis via glucocorticoid metabolite assay using a $5 \alpha-$

260 pregnane-3 $\beta, 11 \beta, 21$-triol-20-one antibody enzyme immunoassay (EIA; see Touma et al. 2003).

261 A detailed validation and description of steroid extraction and EIA with red squirrel fecal

262 samples can be found in Dantzer et al. (2010). 
Fecal samples were analyzed across multiple assays and in two different labs $(\mathrm{n}=355$ at

264 University of Toronto Scarborough and $n=348$ at University of Michigan) but using the same

265 protocol. We confirmed that our measures of FCM concentrations were highly repeatable across

266 assays or labs through the following. First, a separate group of fecal samples ( $\mathrm{n}=128$ samples)

267 were analyzed in both labs and the optical density of these samples were closely correlated

268 (Pearson correlation $=0.88$ ). This indicates that the data were comparable, but we also included a

269 covariate in our statistical models for where the data were analyzed (see below). Second, using

270 pooled samples that were run repeatedly on different plates $(n=115)$, we found that the

271 estimates of optical density for these pool samples were highly repeatable $(R=0.85,95 \% \mathrm{CI}=$

272 0.54-0.93). Finally, using a linear mixed-effects model, we partitioned the variance in the optical

273 density recorded for the pooled samples that were run across these different plates. We found

274 that most of the variance was due to the sample itself $(85.1 \%)$ with relatively little of it being

275 explained by intra-assay variation as all samples were run in duplicate (4.9\%) or by inter-assay

276 variation (9.9\%). Together, this indicates that our measures of FCM concentrations should be

277 comparable across assays and across labs. See Table 2 for a representation of how sample sizes

278 were broken down in each dataset.

$280 \quad$ Statistical methods

281 All statistical analyses were conducted in $\mathrm{R}$ version 3.4.3 (R Core Team 2016). For the

282 OF and MIS trials, we used two principal components analyses to reduce the redundancy among

283 behavioral measurements and calculate composite behavioral scores for each trial, as we have

284 done previously in this system (Boon et al. 2007, 2008; Taylor et al. 2012, 2014; Kelley et al.

285 2015). To conduct the principal components analyses with correlation matrices, we used the $\mathrm{R}$

286 package 'ade4' version 1.7-10 (Dray and Dufour 2007). By reducing the multiple behaviors 
observed down to one metric for each trial, we were able to assess the primary variation among

288 individuals along those axes. All further analyses used the scores calculated from the principal

289 component loadings (Supplementary Material Table S2) for each trial. From the OF trial, we

290 interpreted the first principal component as a measure of overall 'activity', as it has previously

291 been interpreted in this population (Boon et al. 2007, 2008; Taylor et al. 2012, 2014). In our data

292 set, the first component explained $64 \%$ of the variation in behavior across OF trials. From the

293 MIS trial, we interpreted the first principal component as a measure of 'aggression', as it has also

294 previously been interpreted (Boon et al. 2007, 2008; Taylor et al. 2012, 2014). In our data set,

295 the first component explained $60 \%$ of the variation in behavior across MIS trials.

Because we were interested in an estimate of the covariance of FCM concentrations and

297 personality, we used a multivariate framework to conservatively address how the two types of

298 stress responses interact, as explained in Houslay and Wilson (2017). In this study, we were

299 interested in how FCM concentrations and behavioral traits co-varied among individuals. To

300 investigate this in a multivariate framework, we used a Bayesian generalized linear mixed effects

301 multivariate model based on a Markov chain Monte Carlo algorithm with the R package

302 'MCMCglmm' version 2.25 (Hadfield 2010) to assess the relationship between FCM

303 concentrations and behavior. All fecal cortisol metabolite concentration data were ln-transformed

304 to improve normality of residuals.

305 For docility analyses, we used measurements of docility paired with the FCM

306 concentrations of that trapping event. Using a bivariate generalized linear mixed-effects model,

307 we asked whether individuals with higher mean FCM concentrations have higher mean docility

308 scores (among-individual covariance), and whether individual observations of FCM

309 concentration and docility relative to the individual's mean concentrations were correlated

310 (within-individual covariance). Within-individual covariance indicates how the FCM 
311 concentrations and docility scores of one individual covary across multiple observations for that

312 individual; in essence if we have multiple unique measurements of FCM concentration and

313 docility from one individual, does the docility score predict FCM concentrations on that day? In

314 contrast, among-individual covariance measures the relationship between FCM concentration

315 and docility across individuals in the population; in other words, does an individual's average

316 docility score predict its average FCM concentration? The bivariate model for docility and FCM

317 concentration included fixed effects of study grid (control or high-density), sex, Julian date of

318 trapping event (continuous), trial number, breeding status (breeding/non-breeding/lactating), and

319 a variable to indicate where the fecal sample was processed (UT Scarborough/UM). Docility

320 measurements were taken across multiple trapping events for a squirrel, therefore we included

321 trial number to control for any variation caused by habituation to the process of being trapped

322 and restrained in the bag (Boon et al., 2007; Taylor et al., 2012). We specified in the model to

323 estimate the fixed effects of Julian date of trapping event and the location of fecal sample

324 processing for only FCM concentration. These fixed effects were included because they have

325 previously been shown to influence FCM concentration in red squirrels (Dantzer et al. 2010,

326 2013), and thus were included to control for variation among these variables. Although the

327 correlation between UT Scarborough and UM samples was high (0.88), we included location of

328 fecal sample processing to account for any minor variation between the locations.

329 Because we only had one measurement of aggression and activity per individual, we were

330 unable to estimate the within-individual covariance between FCM concentration and the

331 activity/aggression of that individual. Thus, the bivariate models for activity and aggression were

332 structured to control for only one individual activity and aggression score per individual, and

333 only estimate among-individual covariance. The models for activity and aggression included the

334 same fixed effects as the model for docility, except trial number was not included. All trials were 
335 the first trial in the lifetime of that individual, so there is no variance in novelty of the arena

336 across individuals. Again, we estimated fixed effects of the Julian date of trapping event and

337 location of fecal sample processing for only FCM concentration. With this model structure, we

338 were able to more precisely control for variation in FCM concentration due to reproductive

339 condition and time of year.

340 We fit all bivariate MCMCglmm models with uninformative priors (as in Houslay and

341 Wilson 2017) for 2,100,000 iterations with the first 100,000 discarded, and 1 out of every 1,000

342 of the remaining iterations used for parameter estimations. Credible intervals (95\%) around the

343 correlation were based on the MCMC chain iterations. To confirm convergence using a

344 combination of methods, as suggested in a comparative review (Cowles and Carlin 1996), we ran

345 all MCMCglmm models three times for comparison using the Gelman-Rubin statistic (Gelman

346 and Rubin 1992), and we also ran the Geweke diagnostic (Geweke 1992). All models passed

347 both diagnostics for convergence.

Data availability

350 The datasets analyzed during the current study available from the corresponding author on

351 reasonable request.

353 Results

Our results indicate that docility, activity, and aggression did not co-vary with FCM

355 concentrations among individuals. Using a bivariate generalized linear mixed effects model

356 approach, the within-individual covariance indicated that an individual's FCM concentrations

357 did not correlate with docility $(r=0.020, \mathrm{CI}=[-0.14,0.28])$. Our models also indicated that

358 among individuals, FCM concentrations did not correlate with docility $(r=0.14, \mathrm{CI}=[-0.64$, 
$0.83]$, Figure 1$)$, activity $(r=0.15, \mathrm{CI}=[-0.17,0.47]$, Figure 2$)$ or aggression $(r=0.29, \mathrm{CI}=[-$ 0.098, 0.56], Figure 2) (Table 3). Regardless of the statistical significance of these relationships,

361 the direction of the observed effect was opposite to the predicted relationship between behavior

362 and FCM concentrations. The direction of these correlations suggest more active and more

363 aggressive squirrels may have higher FCM concentrations, but this is not conclusive due to

364 confidence intervals overlapping zero.

\section{Discussion}

We demonstrated that the behavioral coping style (represented by three behaviors) and one measure of the physiological stress response (FCM concentrations) did not co-vary in a freeranging mammal. Independent variation between the behavioral and physiological stress responses supports the two-tier model of coping strategies proposed by Koolhaas et al. (2010). response anywhere along the proactive-reactive continuum but independent of their physiological stress response, which can range from a low to a high HPA axis activity. Contrary

375 did not always exhibit lower HPA axis activity than reactive individuals. In fact, the parameter

376 estimates were in the opposite direction from those predicted by the unidimensional model.

377 Specifically, the unidimensional model predicts that a more active behavioral stress response and

378 HPA axis activity should be negatively correlated and we found that they were instead positively

379 correlated, though again these confidence intervals overlapped zero. Although we did find that

380 the three behavioral measures were phenotypically correlated (see Supplementary Material),

381 physiological stress, as measured by FCM concentration, does not appear to be the pleiotropic 382 mechanism causing this covariation. 
Previous studies that have found behavior and HPA axis reactivity are linked have used a

384 different statistical framework than our study. Thus, it is possible our results are simply the

385 outcome of using a more conservative statistical test. However, our results were robust across

386 statistical techniques as we also ran the same models using a different statistical technique (linear

387 mixed effects models) that has been used in previous studies (e.g. Lendvai et al. 2011; Montiglio

388 et al. 2012). These results from the linear mixed effects models (Supplementary Material Table

389 S5) and those from the bivariate models (presented above) both support the hypothesis that

390 behavior and physiology are independent in our study.

391 Our study contributes to an emerging trend of a lack of a strong relationship between

392 behavioral and physiological stress responses in wild and laboratory animals (reviewed by Raulo

393 and Dantzer 2018). For example, wild alpine marmots (Marmota marmota) exhibit a lack of

394 among-individual correlation between activity and plasma cortisol concentrations, as well as

395 between docility and plasma cortisol (Ferrari et al. 2013). Likewise, docility and exploration

396 were not correlated with a change in plasma cortisol in response to a stressor in plateau pika

397 (Ochotona curzoniae: Qu et al. 2018). Additional studies measuring fecal glucocorticoid

398 metabolites demonstrate that HPA axis activity does not correlate with shy-bold behavioral types

399 in wild flycatchers (Ficedula albicollis; Garamszegi et al. 2012), or with exploration/activity in

400 Belding's ground squirrels (Spermophilus beldingi; Dosmann et al. 2015). In captivity, Holstein

401 Friesian heifer calves (Bos taurus) HPA axis reactivity to ACTH is not correlated with their

402 response to novelty (Van Reenen et al. 2005).

403 The unidimensional model posits that both HPA axis activity and reactivity should be

404 lower in proactive animals (Koolhaas et al. 1999). However, it should be noted that

405 measurements of fecal glucocorticoid metabolites in red squirrels may not allow for direct

406 measurement of the reactivity of the HPA axis, which may correlate more strongly with 
407 behavioral stress responses compared to basal regulation (Baugh et al. 2012). Although a study

408 on free-ranging eastern chipmunks (Tamias striatus) showed evidence supporting covariance of

409 behavioral response and physiological stress response from fecal samples, the study used only

410 one metric of physiological stress (coefficient of variation of fecal glucocorticoid metabolites)

411 per individual (Montiglio et al. 2012). This statistical method was limiting in that it did not

412 consider the uncertainty around each individual's measure of HPA axis activity. Our research

413 expands upon the chipmunk study by using more conservative statistical methods, which were

414 not widely used until recently (Houslay and Wilson 2017), in addition to linear models and

415 multiple behavioral assays to establish coping styles. Using both of these approaches, we showed

416 that the behavioral coping style (comprised of three correlated behaviors) does not covary with

417 one measure of physiological stress. We acknowledge that the studies included in Table 1 are

418 across multiple taxa, behaviors, and HPA axis activity measurements. This likely contributes to

419 the equivocal nature of support for these models in wild animals. Though we focused only on

420 wild animals in our brief review (Table 1), empirical studies using laboratory animals also

421 include variation in measurements. Due to the large variability across studies in measurements of

422 HPA axis activity and behavior, perhaps a less generalized model of the relationship between

423 behavior and physiological stress may be more predictive for future studies than our current

424 models.

425 Our study was conducted using adult red squirrels. In this population, high juvenile

426 mortality results in a high opportunity for selection during the first year of life (McAdam et al.

427 2007). Due to these strong selective pressures, we must consider the possibility that selection

428 may have already eroded the (co)variance of physiological and behavioral stress responses in

429 surviving adults. For example, perhaps juveniles with high covariance of the physiological and

430 behavioral stress response were unable to adaptively respond to environmental conditions, 
431 whereas juveniles with low covariance were able to adaptively respond to conditions with the

432 two stress responses decoupled. Additionally, these selective pressures fluctuate across years

433 because red squirrels rely on a masting food source (white spruce) that goes through episodes of

434 booms and busts in production of reproductive cones (McAdam and Boutin 2003; Fletcher et al.

435 2010). Following the masting of spruce trees, squirrel populations increase in density, which may

436 generate density-dependent selection on juvenile traits (Dantzer et al. 2013; Fisher et al. 2017).

437 These fluctuations in selection may maintain genetic variation in behavioral traits in this

438 population (Taylor et al. 2014), and, if a pleiotropic hormone was the mechanism underlying

439 these behavioral correlations, it could limit an adaptive behavioral response to this fluctuating

440 selection if the selective forces on hormone levels and the behavior push in opposite directions

441 (Ketterson and Nolan Jr. 1999; McGlothlin and Ketterson 2008). For example, if a high activity

442 is beneficial in one environmental condition but high HPA axis reactivity is not, a strong

443 correlation between the two traits would constrain an individual's ability to show an adaptive

444 behavioral response to the current environmental conditions. Recent work, however, suggests a

445 hormonal pleiotropic relationship is likely not powerful enough to constrain independent

446 evolution of two traits (Dantzer and Swanson 2017). Alternatively, if the hormone does not show

447 a pleiotropic relationship with behavior and selection for both is working in the same direction,

448 then the absence of a correlation could slow their adaptive response relative to a situation with a

449 positive pleiotropic relationship between the two traits (Ketterson et al. 2009).

450 We also must consider the possibility that different behavioral traits are favored at

451 different life stages. Additional work in this study system has shown wider variation in these

452 behavioral traits among juvenile squirrels, with individuals at both extremes of the proactive-

453 reactive continuum, and individuals regress to the mean as they age (Kelley et al. 2015). This is a

454 potential limitation of our study. Studies using selection lines, and therefore individuals at 
extremes in behavioral response, may therefore be more appropriate for making predictions

456 about juvenile red squirrels, though perhaps not appropriate for predictions about adults. In both

457 Great Tits and rainbow trout (Oncorhynchus mykiss), studies using exploration selection lines

458 have found evidence to support a correlation between behavioral and physiological stress

459 responses (Øverli et al. 2007; Baugh et al. 2012). This suggests the potential to detect a

460 relationship between behavioral and physiological stress responses in juvenile red squirrels,

461 when individuals are more widely dispersed along the proactive-reactive continuum. Future work

462 on the relationship between coping styles and physiological stress responses should investigate

463 the ontogeny of the relationship, and how it may change across life stages.

464 Our study helps establish a foundation to use in exploring the fitness consequences of

465 variability across two axes of the stress response, behavioral and physiological. Building upon

466 this current work, we have an opportunity to explore the mechanisms contributing to each axis of

467 variation independently. For instance, the maternal environment during ontogeny may influence

468 the development of the physiological stress axis, or contribute to the behavioral coping style

469 (reviewed in Meaney 2001). Furthermore, our study provides additional evidence supporting the

470 lack of direct phenotypic correlation between behavioral and physiological stress responses in

471 wild animals exhibiting natural variation in stress responses. Our study, in conjunction with

472 previous studies on these models in wild animals (Table 1), suggests a need for a more

473 generalizable model of the relationship between the behavioral and physiological stress

474 responses, perhaps taking into account the environmental conditions experienced by the species.

475 Further studies in wild animals are needed to explore the mechanisms underlying this variation

476 along the phenotypic landscape of the stress response and the adaptive value of such variation.

477 Studies on the relationship between the behavioral and physiological stress phenotypes in

478 wild animals in variable environments provide insight into the pleiotropic constraints on the 
479 evolutionary paths these populations may take. Our study contributes to a growing body of work

480 in support of the two-tier model of coping styles and physiological stress reactivity and activity

481 in wild and laboratory populations. Specifically, our study demonstrated that the FCM

482 concentration of wild red squirrels is independent of an individual's activity, aggression, and

483 docility. Given that red squirrels in this region experience a fluctuating environment in terms of

484 competitors (Dantzer et al. 2013), food (Boutin et al. 2006), and predators (O’Donoghue et al.

485 1998; Studd et al. 2014) and also fluctuating selection on behavioral traits (Boon et al., 2007;

486 Taylor et al., 2014), having behavioral and physiological responses that are uncorrelated may be

487 beneficial for adapting to this environmental variability. If similar results are found in other

488 species, the lack of a phenotypic relationship between the behavioral and physiological stress

489 responses could have important evolutionary implications, particularly for those species living in

490 fluctuating environments.

492 Ethical approval: All applicable international, national, and/or institutional guidelines for the 493 care and use of animals were followed. All procedures performed in studies involving animals 494 were in accordance with the ethical standards of the institution or practice at which the studies 495 were conducted.

496 Conflict of interest: The authors declare that they have no conflict of interest. 


\section{References}

499 Archer J (1973) Tests for emotionality in rats and mice: A review. Anim Behav 21:205-235. doi:

Baugh AT, Schaper S V., Hau M, et al (2012) Corticosterone responses differ between lines of great tits (Parus major) selected for divergent personalities. Gen Comp Endocrinol 175:488-494. doi: 10.1016/j.ygcen.2011.12.012

Blumstein DT, Daniel JC (2007) Quantifying behavior the JWatcher way. Sinaeur Associates,

Boon AK, Reale D, Boutin S (2008) Personality, habitat use, and their consequences for survival in North American red squirrels Tamiasciurus hudsonicus. Oikos 117:1321-1328. doi:

Boon AK, Réale D, Boutin S (2007) The interaction between personality, offspring fitness and food abundance in North American red squirrels. Ecol Lett 10:1094-1104. doi:

Boutin S, Larsen KW (1993) Does food availability affect growth and survival of males and females differently in a promiscuous small mammal, Tamiasciurus hudsonicus? J Anim Ecol 62:364-370. doi: 10.2307/5367

Boutin S, Wauters LA, McAdam AG, et al (2006) Anticipatory reproduction and population growth in seed predators. Science 314:1928-1930. doi: 10.1126/science.1135520

Carere C, Caramaschi D, Fawcett TW (2010) Covariation between personalities and individual differences in coping with stress: Converging evidence and hypotheses. Curr Zool 56:728741 rate in response to handling stress. Physiol Behav 82:905-912. doi: 
10.1016/j.physbeh.2004.07.009

523 Cockrem JF (2007) Stress, corticosterone responses and avian personalities. J Ornithol 148:169-

178. doi: $10.1007 / \mathrm{s} 10336-007-0175-8$

Cowles MK, Carlin BP (1996) Markov chain Monte Carlo convergence diagnostics: A

comparative review. J Am Stat Assoc 91:883-904. doi: 10.1080/01621459.1996.10476956

527 Dantzer B, Boutin S, Humphries MM, McAdam AG (2012) Behavioral responses of territorial

$$
\text { red squirrels to natural and experimental variation in population density. Behav Ecol }
$$

$$
\text { Sociobiol 66:865-878. doi: 10.1007/s00265-012-1335-2 }
$$

Dantzer B, McAdam AG, Palme R, et al (2010) Fecal cortisol metabolite levels in free-ranging North American red squirrels: Assay validation and the effects of reproductive condition.

Dantzer B, Newman AEM, Boonstra R, et al (2013) Density triggers maternal hormones that

Dantzer B, Swanson EM (2017) Does hormonal pleiotropy shape the evolution of performance

$$
\text { increase adaptive offspring growth in a wild mammal. Science 340:1215-1217. doi: }
$$
and life history traits? Integr Comp Biol 57:372-384. doi: 10.1093/icb/icx064

Dosmann AJ, Brooks KC, Mateo JM (2015) Within-individual correlations reveal link between a behavioral syndrome, condition, and cortisol in free-ranging Belding's ground squirrels. Ethology 121:125-134. doi: 10.1111/eth.12320

Dray S, Dufour A-B (2007) The ade4 package: implementing the duality diagram for ecologists. J Stat Softw 22:. doi: 10.18637/jss.v022.i04

Ferrari C, Pasquaretta C, Carere C, et al (2013) Testing for the presence of coping styles in a wild mammal. Anim Behav 85:1385-1396. doi: 10.1016/j.anbehav.2013.03.030

Fisher DN, Boutin S, Dantzer B, et al. (2017) Multilevel and sex-specific selection on 
competitive traits in North American red squirrels. Evolution 71:1841-1854. doi:

$10.1111 /$ evo. 13270

548 Fletcher QE, Boutin S, Lane JE, et al (2010) The functional response of a hoarding seed predator to mast seeding. Ecology 91:2673-2683. doi: 10.1890/09-1816.1

550 Garamszegi LZ, Rosivall B, Rettenbacher S, et al (2012) Corticosterone, avoidance of novelty, risk-taking and aggression in a wild bird: No evidence for pleiotropic effects. Ethology

Gelman A, Rubin DB (1992) Inference from iterative simulation using multiple sequences. Stat Sci 7:457-472. doi: $10.1214 /$ ss/1177011136

555 Geweke J (1992) Evaluating the accuracy of sampling-based approaches to the calculation of

Gosling SD (2001) From mice to men: what can we learn about personality from animal research? Psychol Bull 127:45-86. doi: 10.1037/0033-2909.127.1.45

Hadfield JD (2010) MCMC methods for multi-response generalized linear mixed models: The

562 Hänninen L, Pastell M (2009) CowLog: Open-source software for coding behaviors from digital video. Behav Res Methods 41:472-476. doi: 10.3758/BRM.41.2.472

564 Houslay TM, Wilson AJ (2017) Avoiding the misuse of BLUP in behavioural ecology. Behav Ecol 28:948-952. doi: 10.1093/beheco/arx023

566 Kelley AD, Humphries MM, McAdam AG, Boutin S (2015) Changes in wild red squirrel 567 personality across ontogeny: activity and aggression regress towards the mean. Behaviour 152:1291-1306. doi: 10.1163/1568539X-00003279

569 Ketterson ED, Atwell JW, McGlothlin JW (2009) Phenotypic integration and independence: 
Hormones, performance, and response to environmental change. Integr Comp Biol 49:365379. doi: $10.1093 /$ icb/icp057

572 Ketterson ED, Nolan, Jr. V (1999) Adaptation, exaptation, and constraint: A hormonal perspective. Am Nat 154:S4-S25. doi: 10.1086/303280

574 Koolhaas JM, De Boer SF, Buwalda B, Van Reenen K (2007) Individual variation in coping with stress: A multidimensional approach of ultimate and proximate mechanisms. Brain Behav

Koolhaas JM, de Boer SF, Coppens CM, Buwalda B (2010) Neuroendocrinology of coping styles: Towards understanding the biology of individual variation. Front Neuroendocrinol 31:307-321. doi: 10.1016/j.yfrne.2010.04.001

Koolhaas JM, Korte SM, De Boer SF, et al (1999) Coping styles in animals: Current status in behavior and stress-physiology. Neurosci Biobehav Rev 23:925-935. doi: 10.1016/S0149-

583 Lendvai ÁZ, Bókony V, Chastel O (2011) Coping with novelty and stress in free-living house sparrows. J Exp Biol 214:821-828. doi: 10.1242/jeb.047712

Love OP, Madliger CL, Bourgeon S, et al. (2014) Evidence for baseline glucocorticoids as mediators of reproductive investment in a wild bird. Gen Comp Endocrinol 199:65-69. doi:

Martin JGA, Réale D (2008) Temperament, risk assessment and habituation to novelty in eastern chipmunks, Tamias striatus. Anim Behav 75:309-318. doi: 10.1016/j.anbehav.2007.05.026

590 McAdam AG, Boutin S (2003) Variation in viability selection among cohorts of juvenile red $591 \quad$ squirrels (Tamiasciurus hudsonicus). Evolution 57:1689-1697. doi: 10.1111/j.00143820.2003.tb00374.x

593 McAdam AG, Boutin S, Sykes AK, Humphries MM (2007) Life histories of female red squirrels 
and their contributions to population growth and lifetime fitness. Ecoscience 14:362. doi: 10.2980/1195-6860(2007)14[362:LHOFRS]2.0.CO;2

McGlothlin JW, Ketterson ED (2008) Hormone-mediated suites as adaptations and evolutionary constraints. Philos Trans R Soc B Biol Sci 363:1611-1620. doi: 10.1098/rstb.2007.0002

Meaney MJ (2001) Maternal care, gene expression, and the transmission of individual differences in stress reactivity across generations. Annu Rev Neurosci 24:1161-1192

Montiglio P-O, Garant D, Pelletier F, Réale D (2012) Personality differences are related to longterm stress reactivity in a population of wild eastern chipmunks, Tamias striatus. Anim Behav 84:1071-1079. doi: 10.1016/j.anbehav.2012.08.010

O’Donoghue M, Boutin S, Krebs CJ, et al (1998) Behavioural responses of coyotes and lynx to

Øverli Ø, Sørensen C, Pulman KGT, et al (2007) Evolutionary background for stress-coping styles: Relationships between physiological, behavioral, and cognitive traits in nonmammalian vertebrates. Neurosci Biobehav Rev 31:396-412. doi:

Palme R (2019) Non-invasive measurement of glucocorticoids: Advances and problems. Physiol

Palme R, Touma C, Arias N, et al (2013) Steroid extraction: Get the best out of faecal samples. Wiener Tierärztliche Monatsschrft 100:238-246

613 Qu J, Fletcher QE, Réale D, et al (2018) Independence between coping style and stress reactivity

614 in plateau pika. Physiol Behav 197:1-8. doi: 10.1016/j.physbeh.2018.09.007

615 Raulo A, Dantzer B (2018) Associations between glucocorticoids and sociality across a continuum of vertebrate social behavior. Ecol Evol 1-20. doi: 10.1002/ece3.4059

617 Réale D, Reader SM, Sol D, et al (2007) Integrating animal temperament within ecology and 
evolution. Biol Rev 82:291-318. doi: 10.1111/j.1469-185X.2007.00010.x

619 Romero LM, Dickens MJ, Cyr NE (2009) The reactive scope model - A new model integrating homeostasis, allostasis, and stress. Horm Behav 55:375-389. doi:

622 Sapolsky RM, Romero LM, Munck AU (2000) How do glucocorticoids influence stress responses? Integrating permissive, suppressive, stimulatory, and preparative actions. Endocr

Sheriff MJ, Dantzer B, Delehanty B, et al (2011) Measuring stress in wildlife: Techniques for

Sih A, Bell AM, Johnson JC, Ziemba RE (2004) Behavioral syndromes: An integrative overview. Q Rev Biol 79:241-277. doi: 10.1086/422893

Siracusa E, Morandini M, Boutin S, et al (2017) Red squirrel territorial vocalizations deter intrusions by conspecific rivals. Behaviour 154:1259-1273. doi: 10.1163/1568539X-

Stamps J, Groothuis TGG (2010) The development of animal personality: Relevance, concepts and perspectives. Biol Rev 85:301-325. doi: 10.1111/j.1469-185X.2009.00103.x

Stöwe M, Rosivall B, Drent PJ, Möstl E (2010) Selection for fast and slow exploration affects

Steimer T, Driscoll P (2003) Divergent stress responses and coping styles in psychogenetically selected Roman high-(RHA) and low-(RLA) avoidance rats: Behavioural, neuroendocrine baseline and stress-induced corticosterone excretion in Great tit nestlings, Parus major. Horm Behav 58:864-871. doi: 10.1016/j.yhbeh.2010.08.011 reproductive failure in red squirrels. J Anim Ecol 84:249-259. doi: 10.1111/1365- 
643 Taylor RW (2012) Quantitative genetics, selection, mate choice and red squirrel behavior in a

644 fluctuating environment. Michigan State University

645 Taylor RW, Boon AK, Dantzer B, et al. (2012) Low heritabilities, but genetic and maternal

646 correlations between red squirrel behaviours. J Evol Biol 25:614-624. doi: 10.1111/j.1420-

$6479101.2012 .02456 . x$

648 Taylor RW, Boutin S, Humphries MM, McAdam AG (2014) Selection on female behaviour

649 fluctuates with offspring environment. J Evol Biol 27:2308-2321. doi: 10.1111/jeb.12495

650 Touma C, Sachser N, Möstl E, Palme R (2003) Effects of sex and time of day on metabolism and 651 excretion of corticosterone in urine and feces of mice. Gen Comp Endocrinol 130:267-278.

652 doi: $10.1016 / \mathrm{S} 0016-6480(02) 00620-2$

653 Van Reenen CG, O’Connell NE, Van der Werf JTN, et al (2005) Responses of calves to acute

654 stress: Individual consistency and relations between behavioral and physiological measures.

655 Physiol Behav 85:557-570. doi: 10.1016/j.physbeh.2005.06.015

656

657 
658 Figure 1. Stress reactivity and activity, as measured by average FCM concentration, is not

659 predicted by docility in North American red squirrels. Size of the points represents number of

660 fecal samples included for that individual.

661 Figure 2. Stress reactivity and activity, as measured by average FCM concentration, is not

662 predicted by activity or aggression in North American red squirrels. Activity and aggression are

663 from scores determined by the principal component analyses. Size of the points represents

664 number of fecal samples included for that individual.

665

666 
7 Table 1. Review of field studies testing for the covariance in behavioral coping styles and HPA activity

This non-comprehensive table includes studies conducted with natural populations testing the unidimensional (Koolhaas et al. 1999b)

9 and two-tier models (Koolhaas et al. 2010) of the among individual relationship between behavioral coping styles ('Behavioral Trait') and

0 HPA axis activity ('Physiological Measurement'). The first section includes studies that support the main prediction from the unidimensional

1 model that more proactive individuals have lower HPA axis activity. The second section includes studies that are contrary to the main

2 prediction from the unidimensional model that more proactive individuals would have lower HPA axis activity. These studies do show that

3 behavior and HPA activity covary, but the relationship is in the opposite of the direction predicted by the unidimensional model with

4 proactive individuals having lower HPA axis activity. The third section includes studies that support the two-tier model that predicts that

5 behavior and HPA axis activity do not covary in either direction. Correlations or estimates are included if available in the corresponding

6 manuscript. Confidence/credible intervals are included if available; if not, p-values are included when available. If the confidence/credible

7 interval overlapped zero, we interpreted this as the behavior trait measured and the physiological measurement did not covary. Non-true

8 baseline samples were the first sample collected but involved some handling or trapping stress. $(\mathrm{n}=$ sample size of individuals, NS $=$ non-

9 significant $(p>0.05), \mathrm{FCM}=$ fecal cortisol metabolites, $\mathrm{DEX}=$ dexamethasone (synthetic corticosteroid that exerts negative feedback on the

$0 \quad \mathrm{HPA}$ axis), $\mathrm{ACTH}=$ adrenocorticotropic hormone that increases adrenocortical activity) 


\section{Species}

Behavioral Trait

Physiological Measurement

n Correlation or Estimate [CI]

Evidence supporting the predictions of the unidimensional model that behavioral and physiological traits are negatively correlated

\begin{tabular}{|c|c|c|c|c|}
\hline $\begin{array}{l}\text { Great Tits (Parus major) } \\
\text { (Baugh et al. 2017) }\end{array}$ & Exploration & $\begin{array}{l}\text { Blood corticosterone (ACTH challenge } \\
\text { induced) }\end{array}$ & 85 & $\mathrm{R}^{2}=0.051, p=0.04$ \\
\hline Great Tits (Parus major) & Exploration & $\begin{array}{l}\text { Blood corticosterone (90-min handling- } \\
\text { restraint stress-induced) }\end{array}$ & 16 & $\mathrm{~b}=-0.417, p=0.015$ \\
\hline (Baugh, van Oers, Naguib, \& Hau, 2013) & Exploration & $\begin{array}{l}\text { Blood corticosterone (area under the stress- } \\
\text { induced curve) }\end{array}$ & 16 & $\mathrm{~b}=-24.66, p=0.007$ \\
\hline $\begin{array}{l}\text { Belding's ground squirrels (Urocitellus belingi) } \\
\text { (Clary et al. 2014) }\end{array}$ & Vigilance & FCM (nominal baseline) & 12 & $\mathrm{~b}=2.109[0.17,4.05]$ \\
\hline $\begin{array}{l}\text { Brook charr (Salvelinus fontinalis) } \\
\quad \text { (Farwell et al. 2014) }\end{array}$ & Activity & $\begin{array}{l}\text { Whole-body cortisol (baseline and } \\
\text { handling/novel object stress-induced samples) }\end{array}$ & 66 & $\mathrm{NA}^{*}$ \\
\hline $\begin{array}{l}\text { House Sparrows (Passer domesticus) } \\
\text { (Lendvai et al. 2011) }\end{array}$ & Hovering & $\begin{array}{l}\text { Blood corticosterone ( } 30 \text { min handling- } \\
\text { restraint stress-induced) }\end{array}$ & 18 & Pearson's $r=-0.58, p=0.017$ \\
\hline $\begin{array}{l}\text { Eastern chipmunks (Tamias striatus) } \\
\text { (Montiglio et al. 2012) }\end{array}$ & Exploration & FCM (coefficient of variation) & 58 & $b=-13.68[-27.62,-4.45]$ \\
\hline $\begin{array}{l}\text { Plateau pika (Ochotona curzoniae) } \\
\text { (Qu et al. 2018) }\end{array}$ & Shyness & Blood cortisol (true baseline) & 292 & posterior $\mathrm{R}=0.45[0.09,0.66]$ \\
\hline
\end{tabular}

\section{Evidence in the opposite direction of predictions of the unidimensional model}

\begin{tabular}{|c|c|c|c|c|}
\hline $\begin{array}{l}\text { Poeciliid fish (Brachyrhaphis episcopi) } \\
\text { (Archard et al. 2012) }\end{array}$ & Exploration, Activity & $\begin{array}{l}\text { Water-borne cortisol (open-field stress- } \\
\text { induced) }\end{array}$ & 96 & Pearson's $r=-0.29, p=0.005$ \\
\hline $\begin{array}{l}\text { Great Tits (Parus major) } \\
\text { (Baugh et al. 2013) }\end{array}$ & Exploration & Blood corticosterone (true baseline) & 82 & $\mathrm{~b}=0.536, p=0.003$ \\
\hline $\begin{array}{l}\text { Alpine marmots (Marmota marmota) } \\
(\text { Costantini et al. 2012) }\end{array}$ & Exploration, Activity & Blood cortisol (non-true baseline) & 28 & $\begin{array}{l}\mathrm{b}=0.54, \\
\text { Fischer } C \text {-statistic model selection }\end{array}$ \\
\hline $\begin{array}{c}\text { Graylag Geese (Anser anser) } \\
\text { (Kralj-Fišer et al. 2009) }\end{array}$ & Aggression & FCM (handling stress-induced) & 10 & Spearman's $\mathrm{r}=0.782, p=0.008$ \\
\hline
\end{tabular}




\begin{tabular}{|c|c|c|c|c|}
\hline Species & Behavioral Trait & Physiological Measurement & n & Correlation or Estimate [CI] \\
\hline \multirow{2}{*}{$\begin{array}{l}\text { Great Tits (Parus major) } \\
\text { (Baugh, Davidson, Hau, \& van Oers, 2017) }\end{array}$} & Exploration & $\begin{array}{l}\text { Blood corticosterone (handling-restrain stress- } \\
\text { induced) }\end{array}$ & 85 & $\mathrm{R}^{2}=0.03, p=0.14$ \\
\hline & Exploration & Blood corticosterone (DEX challenge response) & 85 & $\mathrm{R}^{2}=0.02, p=0.20$ \\
\hline $\begin{array}{l}\text { Belding's ground squirrels (Urocitellus belingi) } \\
\text { (Clary et al., 2014) }\end{array}$ & Exploration & FCM (non-true baseline) & 12 & $\mathrm{~b}=-0.76[-1.12,0.98]$ \\
\hline $\begin{array}{l}\text { Alpine marmots (Marmota marmota) } \\
\text { (Costantini et al., 2012) }\end{array}$ & Exploration, Activity & $\begin{array}{l}\text { Blood cortisol (pre-restraint to post-restraint } \\
\text { response) }\end{array}$ & 28 & $\mathrm{NA}^{* *}$ \\
\hline \multirow{3}{*}{$\begin{array}{l}\text { Belding's ground squirrels (Urocitellus belingi) } \\
\text { (Dosmann et al. 2015) }\end{array}$} & Activity & FCM (non-true baseline) & 157 & posterior $\mathrm{R}=-0.007,[-0.123,0.095]$ \\
\hline & Exploration & FCM (non-true baseline) & 157 & posterior $\mathrm{R}=-0.046,[-0.175,0.036]$ \\
\hline & Docility & FCM (non-true baseline) & 157 & posterior $\mathrm{R}=0.016,[-0.077,0.139]$ \\
\hline \multirow{3}{*}{$\begin{array}{l}\text { Alpine marmots (Marmota marmota) } \\
\text { (Ferrari et al. 2013) }\end{array}$} & Activity & Blood cortisol (non-true baseline) & 146 & posterior $\mathrm{R}=0.04,[-0.56,0.71]$ \\
\hline & Impulsivity & Blood cortisol (non-true baseline) & 146 & posterior $\mathrm{R}=0.08,[-0.68,0.62]$ \\
\hline & Docility & Blood cortisol (non-true baseline) & 146 & posterior $\mathrm{R}=0.14,[-0.64,0.63]$ \\
\hline \multirow{3}{*}{$\begin{array}{l}\text { Collard Flycatchers (Ficedula albicollis) } \\
\text { (Garamszegi et al. 2012) }\end{array}$} & Novel object avoidance & FCM (non-true baseline) & 51 & Pearson's $\mathrm{r}=-0.017,[-0.291,0.260]$ \\
\hline & Aggression & FCM (non-true baseline) & 56 & Pearson's $r=-0.076,[-0.332,0.191]$ \\
\hline & Risk-taking & FCM (non-true baseline) & 54 & Pearson's $r=0.074,[-0.198,0.335]$ \\
\hline \multirow{11}{*}{$\begin{array}{l}\text { Nazca Boobies (Sula granti) } \\
\text { (Grace and Anderson 2014) }\end{array}$} & Gardening (non-social) & Blood corticosterone (true baseline) & 222 & $\mathrm{~b}=0.26,[-0.09,0.61]$ \\
\hline & Shaking (non-social) & Blood corticosterone (true baseline) & 222 & $\mathrm{~b}=-0.06,[-0.25,0.13]$ \\
\hline & Aggression (non-social) & Blood corticosterone (true baseline) & 222 & $\mathrm{~b}=0.19,[-0.07,0.45]$ \\
\hline & Gardening (non-social) & $\begin{array}{l}\text { Blood corticosterone (maximum value across } 4 \\
\text { time points during capture-restraint) }\end{array}$ & 222 & $\mathrm{~b}=-0.30,[-0.98,0.38]$ \\
\hline & Shaking (non-social) & $\begin{array}{l}\text { Blood corticosterone (maximum value across } 4 \\
\text { time points during capture-restraint) }\end{array}$ & 222 & $\mathrm{~b}=-0.08,[-0.44,0.28]$ \\
\hline & Aggression (non-social) & $\begin{array}{l}\text { Blood corticosterone (maximum value across } 4 \\
\text { time points during capture-restraint) }\end{array}$ & 222 & $\mathrm{~b}=-0.07,[-0.35,0.21]$ \\
\hline & Gardening (non-social) & $\begin{array}{l}\text { Blood corticosterone (area under the curve } \\
\text { across } 4 \text { time points during capture-restraint) }\end{array}$ & 222 & $\mathrm{~b}=-0.16,[-0.7,0.38]$ \\
\hline & Shaking (non-social) & $\begin{array}{l}\text { Blood corticosterone (area under the curve } \\
\text { across } 4 \text { time points during capture-restraint) }\end{array}$ & 222 & $\mathrm{NA}, \mathrm{CI}$ in figure includes 0 \\
\hline & Aggression (non-social) & $\begin{array}{l}\text { Blood corticosterone (area under the curve } \\
\text { across } 4 \text { time points during capture-restraint) }\end{array}$ & 222 & $\mathrm{NA}, \mathrm{CI}$ in figure includes 0 \\
\hline & Gardening (social) & Blood corticosterone (true baseline) & 222 & $\mathrm{~b}=0.20,[0.02,0.38]$ \\
\hline & Shaking (social) & Blood corticosterone (true baseline) & 222 & $\mathrm{~b}=-0.04[-0.18,0.1]$ \\
\hline
\end{tabular}




\begin{tabular}{|c|c|c|c|c|}
\hline Species & Behavioral Trait & Physiological Measurement & $\mathbf{n}$ & Correlation or Estimate [CI] \\
\hline & Aggression (social) & Blood corticosterone (true baseline) & 222 & $\mathrm{~b}=-0.02[-0.11,0.07]$ \\
\hline & Gardening (social) & $\begin{array}{l}\text { Blood corticosterone (maximum value across } 4 \\
\text { time points during capture-restraint) }\end{array}$ & 222 & $\mathrm{~b}=-0.03[-0.23,0.17]$ \\
\hline & Shaking (social) & $\begin{array}{l}\text { Blood corticosterone (maximum value across } 4 \\
\text { time points during capture-restraint) }\end{array}$ & 222 & $\mathrm{~b}=0.04[-0.2,0.28]$ \\
\hline & Aggression (social) & $\begin{array}{l}\text { Blood corticosterone (maximum value across } 4 \\
\text { time points during capture-restraint) }\end{array}$ & 222 & $b=-0.01[-0.02,0]$ \\
\hline & Gardening (social) & $\begin{array}{l}\text { Blood corticosterone (area under the curve } \\
\text { across } 4 \text { time points during capture-restraint) }\end{array}$ & 222 & $\mathrm{~b}=0.02[-0.15,0.19]$ \\
\hline & Shaking (social) & $\begin{array}{l}\text { Blood corticosterone (area under the curve } \\
\text { across } 4 \text { time points during capture-restraint) }\end{array}$ & 222 & $\mathrm{NA}, \mathrm{CI}$ in figure includes 0 \\
\hline & Aggression (social) & $\begin{array}{l}\text { Blood corticosterone (area under the curve } \\
\text { across } 4 \text { time points during capture-restraint) }\end{array}$ & 222 & $\mathrm{NA}, \mathrm{CI}$ in figure includes 0 \\
\hline Graylag Geese (Anser anser) & Aggression & FCM (non-true baseline) & 10 & Spearman's $r=-0.503, \mathrm{NS}$ \\
\hline \multirow[t]{2}{*}{ (Kralj-Fišer et al. 2009) } & Sociability & FCM (non-true baseline) & 10 & Spearman's $r=-0.212, \mathrm{NS}$ \\
\hline & Sociability & FCM (handling stress-induced) & 10 & Spearman's $r=-0.127, \mathrm{NS}$ \\
\hline House Sparrows (Passer domesticus) & Exploration & $\begin{array}{l}\text { Blood corticosterone ( } 30 \text { min handling- } \\
\text { restraint stress-induced) }\end{array}$ & 18 & Pearson's $\mathrm{r}=-0.07, p=0.797$ \\
\hline \multirow[t]{4}{*}{ (Lendvai et al. 2011) } & Shy-bold & $\begin{array}{l}\text { Blood corticosterone ( } 30 \text { min handling- } \\
\text { restraint stress-induced) }\end{array}$ & 18 & Pearson's $\mathrm{r}=-0.04, p=0.866$ \\
\hline & Exploration & Blood corticosterone (true baseline) & 18 & Pearson's $\mathrm{r}=-0.18, p=0.487$ \\
\hline & Shy-bold & Blood corticosterone (true baseline) & 18 & Pearson's $\mathrm{r}=-0.07, p=0.801$ \\
\hline & Hovering & Blood corticosterone (true baseline) & 18 & Pearson's $\mathrm{r}=-0.14, p=0.573$ \\
\hline Plateau pika (Ochotona curzoniae) & Docility, in cage & Blood cortisol (true baseline) & 292 & posterior $\mathrm{R}=0.25[-0.02,0.63]$ \\
\hline \multirow[t]{6}{*}{ (Qu et al. 2018) } & Docility, in bag & Blood cortisol (true baseline) & 292 & posterior $\mathrm{R}=-0.06[-0.28,0.31]$ \\
\hline & Exploration & Blood cortisol (true baseline) & 292 & posterior $\mathrm{R}=-0.16[-0.52,0.05]$ \\
\hline & Docility, in cage & $\begin{array}{l}\text { Blood cortisol (40 min post-capture change } \\
\text { from baseline) }\end{array}$ & 292 & posterior $\mathrm{R}=0.22[-0.06,0.47]$ \\
\hline & Docility, in bag & $\begin{array}{l}\text { Blood cortisol ( } 40 \text { min post-capture change } \\
\text { from baseline) }\end{array}$ & 292 & posterior $\mathrm{R}=0.16[-0.07,0.48]$ \\
\hline & Exploration & $\begin{array}{l}\text { Blood cortisol (40 min post-capture change } \\
\text { from baseline) }\end{array}$ & 292 & posterior $\mathrm{R}=0.10[-0.42,0.24]$ \\
\hline & Shyness & $\begin{array}{l}\text { Blood cortisol (40 min post-capture change } \\
\text { from baseline) }\end{array}$ & 292 & posterior $\mathrm{R}=-0.23[-0.28,0.22]$ \\
\hline
\end{tabular}


$685 *$ Used AICc model selection approach. All top models included activity as predictor of cortisol.

686 Based on figure in text, the top model indicates more active individuals have less whole-body

687 cortisol.

$688 * *$ Used nested path model selection approach. Based on figure in text, the top model does not

689 include a relationship between change in cortisol and coping style.

690 

cortisol metabolites or FCM). Italics indicate fixed effects estimated for FCM concentration only.

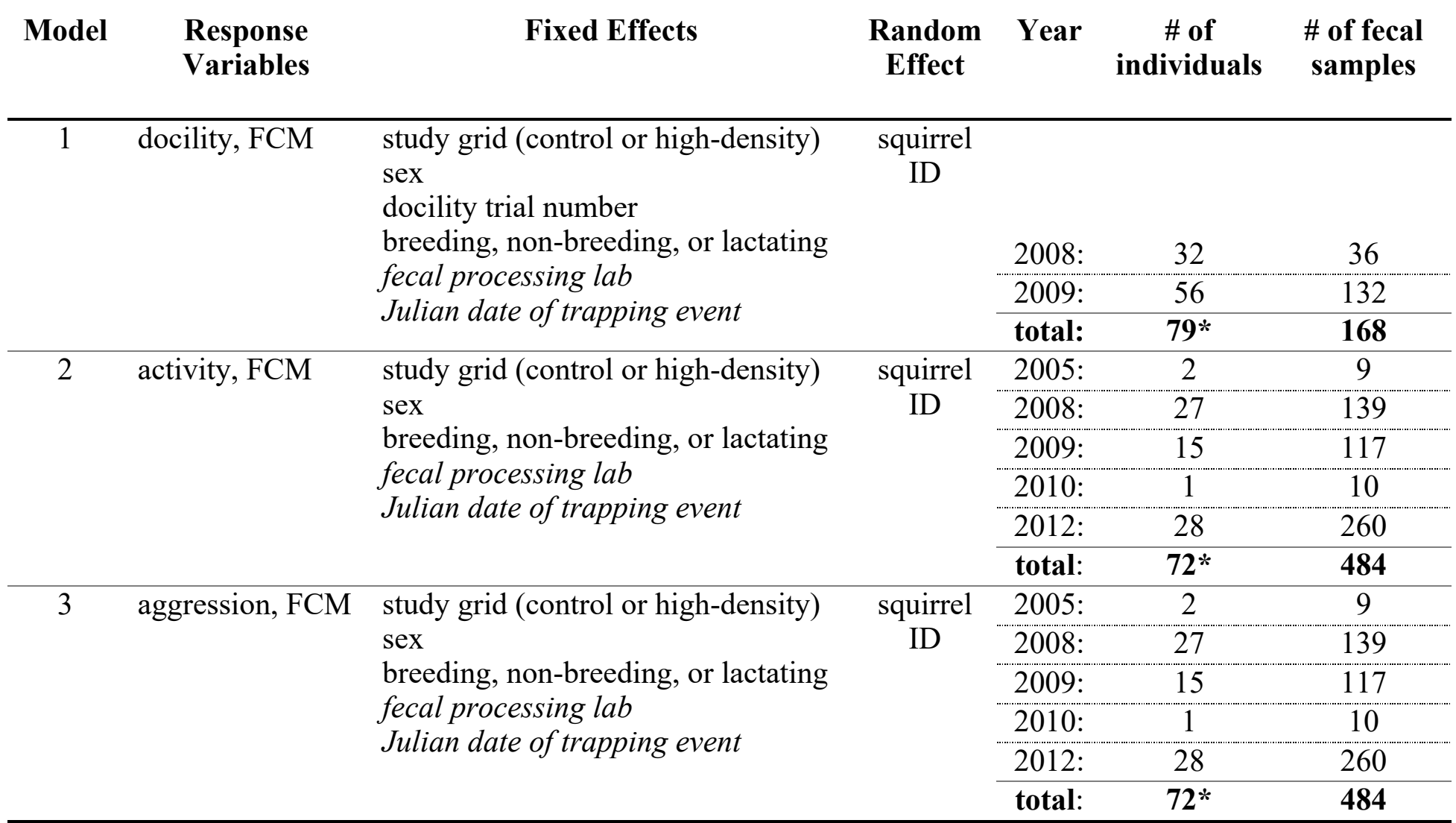




\section{Table 3. Multivariate results for relationships between FCM and behaviors}

697 Results from our three bivariate generalized linear mixed-effects model models to examine the

698 relationships between FCM and each of three behaviors individually (activity and aggression

699 models: $\mathrm{n}=484$ fecal samples; docility model: $\mathrm{n}=168$ fecal samples). Among-individual

700 variances are listed on the diagonal, covariances below and correlations above (with the lower

701 and upper bounds of 95\% CIs in parentheses).

\begin{tabular}{|c|c|c|}
\hline & $\ln (\mathrm{FCM})$ & Docility \\
\hline $\ln (\mathrm{FCM})$ & $\begin{array}{c}0.049 \\
{[1.86-8,0.13]}\end{array}$ & $\begin{array}{c}0.14 \\
{[-0.63,0.83]}\end{array}$ \\
\hline Docility & $\begin{array}{c}0.012 \\
{[-0.074,0.11]}\end{array}$ & $\begin{array}{c}0.40 \\
{[0.15,0.71]}\end{array}$ \\
\hline \multirow[b]{2}{*}{$\ln (\mathbf{F C M})$} & $\ln (\mathrm{FCM})$ & Activity \\
\hline & $\begin{array}{c}0.075 \\
{[0.018,0.14]}\end{array}$ & $\begin{array}{c}0.15 \\
{[-0.17,0.47]}\end{array}$ \\
\hline \multirow[t]{2}{*}{ Activity } & $\begin{array}{c}0.04 \\
{[-0.034,0.11]}\end{array}$ & $\begin{array}{c}0.55 \\
{[0.38,0.73]}\end{array}$ \\
\hline & $\ln (\mathrm{FCM})$ & Aggression \\
\hline $\ln (\mathrm{FCM})$ & $\begin{array}{c}0.077 \\
{[0.016,0.14]}\end{array}$ & $\begin{array}{c}0.29 \\
{[-0.098,0.56]}\end{array}$ \\
\hline Aggression & $\begin{array}{c}0.061 \\
{[-0.03,0.16]}\end{array}$ & $\begin{array}{c}1.00 \\
{[0.68,1.33]}\end{array}$ \\
\hline
\end{tabular}




\section{Figure 1.}

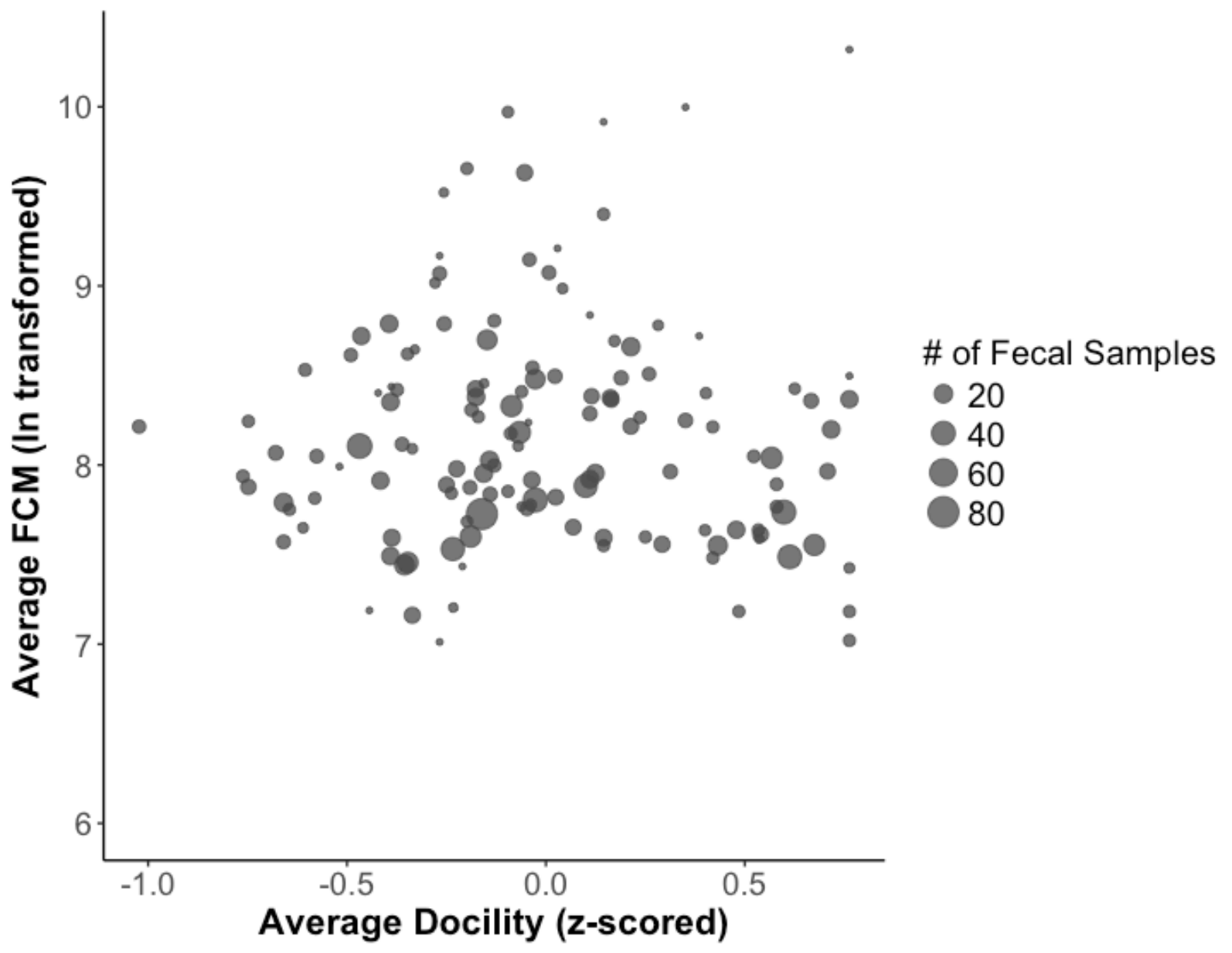


Figure 2.

710
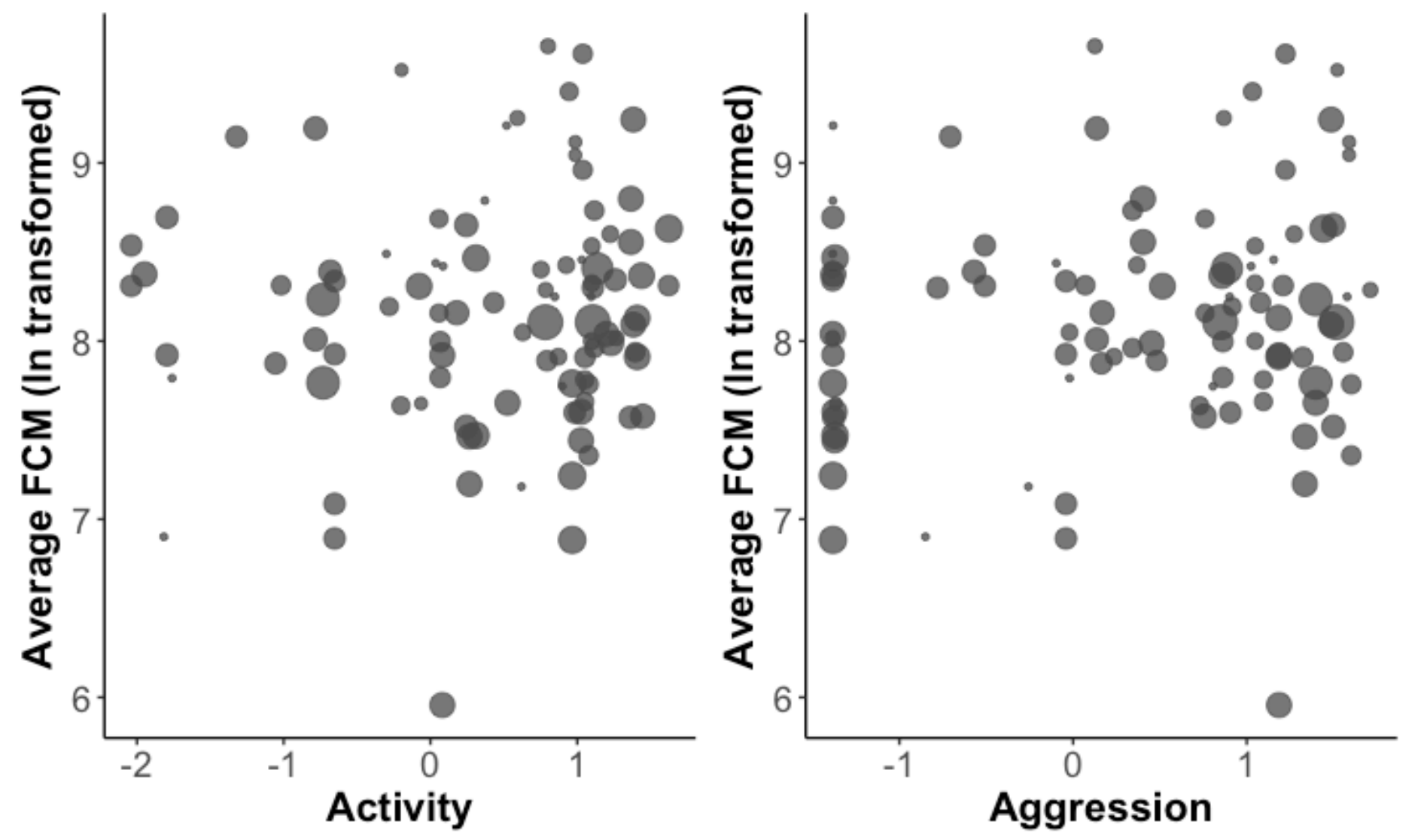

711

Number of Fecal Samples

$10 \bigcirc 20$ 